Original article

\title{
Maintaining skin health and integrity for staff wearing personal protective equipment for prolonged periods: a practical tip sheet
}

\section{Coyer F, Coleman K, Hocking K, Leong T, Levido A and Barakat-Johnson M}

Keywords personal protective equipment, pressure injury, device-related pressure injury, COVID-19

For referencing Coyer $\mathrm{F}$ et al. Maintaining skin health and integrity for staff wearing personal protective equipment for prolonged periods: a practical tip sheet. Wound Practice and Research 2020; 28(2):75-83.

DOI https://doi.org/10.33235/wpr.28.2.75-83

Fiona Coyer* RN, MSc Nursing, PhD

Professor of Nursing, Conjoint appointment with

the School of Nursing Queensland University of

Technology and Royal Brisbane and Women's

Hospital, QLD

Visiting Professor, Institute for Skin Integrity and Infection Prevention, University of Huddersfield, UK Email f.coyer@qut.edu.au

Kerrie Coleman RN, BNSc, MN Clinical (Wound), MN (Chronic Disease NP)

Nurse Practitioner Complex Wound Management, Royal Brisbane and Women's Hospital, QLD

Kathy Hocking RN, Grad Dip (Wound Care) Acting Clinical Nurse Consultant Skin Integrity Service, Royal Brisbane and Women's Hospital, QLD

Tom Leong RN, MNursing

Clinical Nurse Consultant, Skin Integrity and Wound

Management, Royal Prince Alfred Hospital, NSW

Annabel Levido RN, BN, GradCert (Critical Care Nursing), MAppManagament (Nursing)

Clinical Nurse Nursing Research, Intensive Care Services, Royal Brisbane and Women's Hospital, QLD

Michelle Barakat-Johnson RN, MNursing, PhD Skin Integrity Lead, Sydney Local Health District, NSW

Senior Lecturer, Faculty of Medicine and Health, University of Sydney, Camperdown, NSW Adjunct Associate Professor, School of Nursing, Queensland University of Technology, QLD

* Corresponding author

\section{Abstract}

Patient skin injuries associated with medical or therapeutic devices are increasingly reported in the literature. With the coronavirus (COVID-19) pandemic, healthcare staff are wearing personal protective equipment (PPE) for prolonged periods. Anecdotally, cases of healthcare workers' self report of injuries to their face, particularly the bridge of the nose, upper cheek, forehead and above the ears, as a result of extended use of eye protection and masks is increasing. Protecting the skin of frontline healthcare staff is as important as protecting patients' skin. The tip sheet presented in this paper provides staff with a guide in the form of written and visual assistance in order to reduce the risk of device-related pressure injuries (DRPIs) in healthcare staff caused by PPE.

\section{Key points}

What is already known about this topic

- Patient skin injuries related to medical or therapeutic devices are reported in the literature with increasing frequency.

- Healthcare staff caring for COVID-19 positive patients must wear personal protective equipment (PPE) for prolonged periods, resulting in skin injuries seen on their faces and ears caused by masks and eye wear.

- There is scant empirical evidence on staff experiencing PPE-associated pressure injuries.

What this manuscript contributes

- This manuscript reports the rapid development of a tip sheet for staff wearing PPE for prolonged periods to protect their facial skin.

- Pre-emptive skin care practices to reduce the risk of PPEassociated pressure injuries are important to develop and disseminate. 
Figure 1. Clinician wearing PPE.
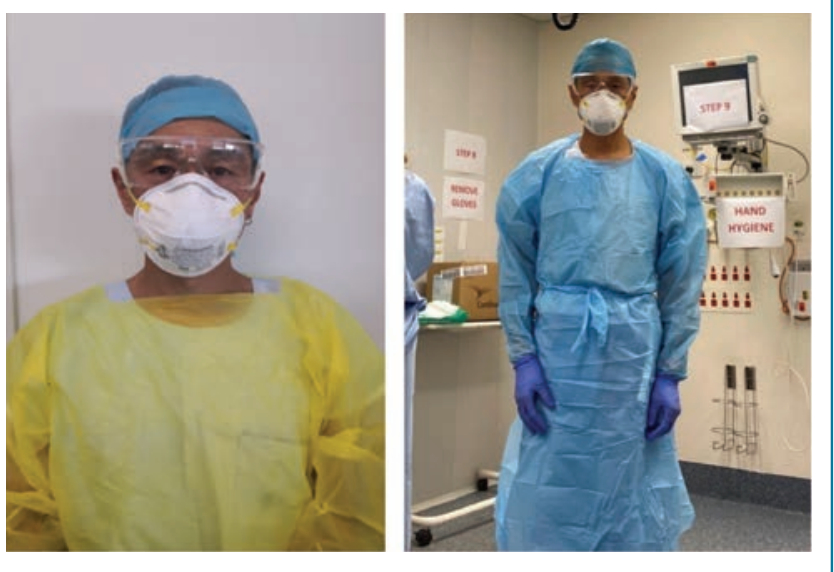

Background

Severe acute respiratory syndrome coronavirus-2 (SARSCOV-2), also known as coronavirus (COVID-19), is a viral, highly infectious disease causing mild, moderate and severe respiratory symptoms. COVID-19 has spread rapidly and widely in mainland China, with significant local transmission occurring in other countries across all continents (excluding Antarctica) and increasing numbers of infections occurring globally. On 11 March 2020, the World Health Organization declared COVID-19 a global pandemic ${ }^{1}$. As at 3 June 2020, COVID-19 global mortality is $6 \%(379,941$ deaths from $6,287,771$ confirmed cases) $)^{2}$. The healthcare response to COVID-19 has mobilised vast numbers of healthcare staff, with facilities now operating dedicated, separate areas or wards to care for COVID-19 positive patients in isolation ${ }^{3,4}$.

Consequently, it is mandatory for staff working in COVID-19 dedicated areas to wear personal protective equipment (PPE) for contact and airborne precautions ${ }^{5-7}$. PPE, in this instance, includes a long-sleeve gown, disposable non-sterile gloves, eye wear (disposable safety glasses and / or full-face visor), respiratory protective equipment (for example N95 respirator masks) and protective hair covers (Figure 1). PPE is intended to protect its user, the healthcare staff, against physical harm or hazards present in the workplace environment. This harm or hazard may be evident from breathing in contaminated air or droplet aerosols and droplet particles or splash to the eyes ${ }^{5}$. Healthcare staff are now faced with wearing PPE for extensive time periods, including 8- and 12-hour shifts. Consequently, staff have reported, largely through a variety of social media platforms, injuries to the skin of their face, particularly the bridge of the nose, upper cheek, forehead and above the ears, as a result of extended wear of eye wear and masks (Figures 2 and 3).

These injuries fall into the category of device-related pressure injuries (DRPI). DRPI was defined by a recent consensus panel as injuries that "involve interaction with a device or object that is in direct or indirect contact with skin or implanted under the skin, causing focal and localised forces that deform the superficial and deep underlying tissues. A device-related pressure ulcer/injury, which is caused by a device or object, is distinct from a pressure injury, which is caused primarily by body weight forces. The localised nature of device forces results in the appearance of skin and deeper tissue damage that mimics that of the device in shape and distribution"8(pS5). DRPI located on the skin are staged using the cutaneous pressure injury Stages 1-4, unstageable or deep tissue pressure injuries ${ }^{9}$. Of late there has been increased attention given to, and reporting of, empirical work related to DRPI ${ }^{10-15}$, leading to the inclusion of this injury in the recent Prevention and treatment of pressure ulcers/ injuries: clinical practice guideline (known as the International guideline) $)^{9}$.

However, literature associated with DRPI is usually made with reference to patients. There is a dearth of literature exploring this phenomenon in healthcare staff wearing PPE. Areas susceptible to unrelieved focal and localised forces that deform the tissues are illustrated in Figure 4. Following the SARS outbreak in 2003, Foo et al. ${ }^{16}$ surveyed healthcare staff and identified that $35 \%$ of staff (109/307) reported adverse skin reactions, including rashes and itch, when

Figure 2. ICU RNs with facial skin injuries from PPE.
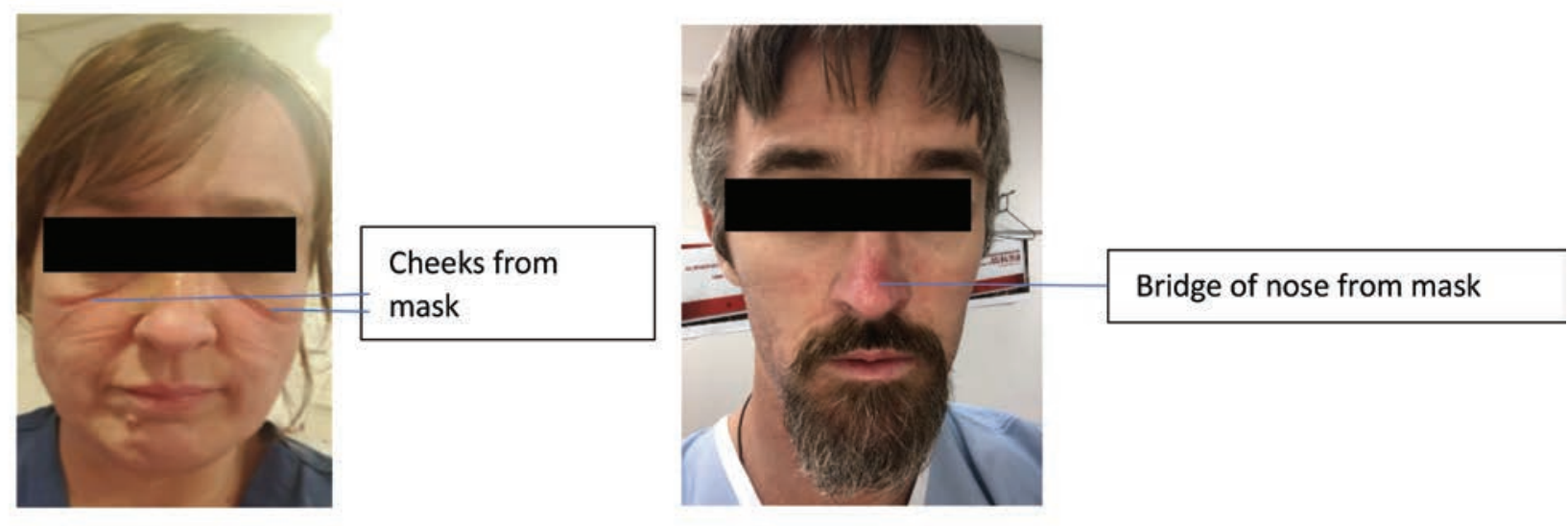
Figure 3. Clinician with areas of pressure after 1 hour of wearing a mask.

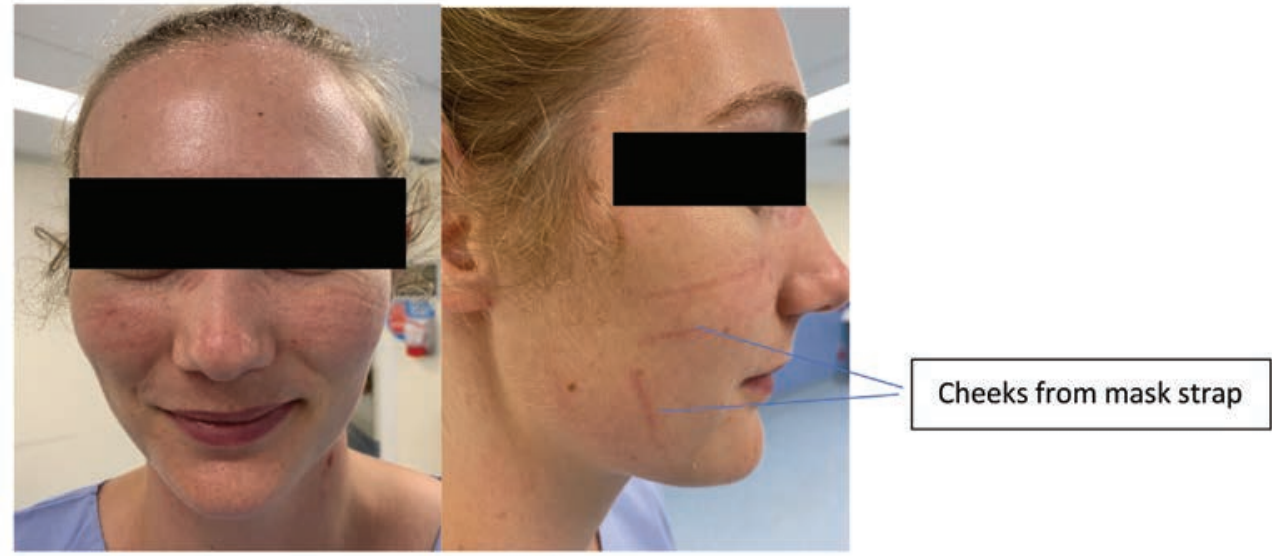

wearing face masks for an average duration of 8 hours per day. Interestingly, Foo and colleagues ${ }^{16}$ did not identify any adverse skin reactions as pressure injuries or DRPI, possibly because of the retrospective nature of their survey which used self-reporting and a lack of a DRPI definition at the time of the publication. These experiences and injuries are similar to those of patients who wear masks for non-invasive ventilation over a prolonged period ${ }^{17}$.

Promoting skin health and maintaining skin integrity for frontline staff wearing PPE for extended and regular periods when caring for COVID-19 patients is paramount. Globally, professional wound care organisations are collaborating to address this issue, and work in this area is emerging rapidly. The Portuguese Wound Management Association (APTFeridas) ${ }^{18}$ released a global consensus statement for the prevention of skin lesions caused by PPE. This is supported by an updated overview from the Nurses Specialising in Wound, Ostomy and Continence Canada (NSWOCC) organisation $^{19}$. Both documents highlight the concern for PPE-related skin injury and outline standardised approaches for healthcare staff to address skin hygiene and injury prevention when wearing PPE. The National Pressure Injury Advisory Panel (NPIAP) in the United States have published a position statement on preventing skin injury with N95 masks ${ }^{20}$ and information tips for staff to consider to protect their skin under the N95 face masks ${ }^{21}$. Of note, the NPIAP position paper does not provide a recommendation for the application of thin prophylactic dressings under face masks, arguing that the risk of COVID-19 infection through this practice has not been determined. Instead, the clinicians are

Figure 4. Areas susceptible to unrelieved focal and localised forces that deform the tissues

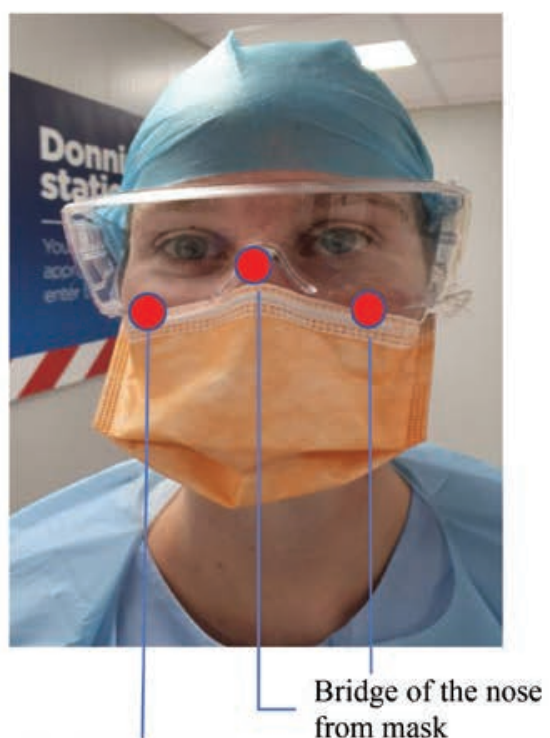

Cheeks from mask strap

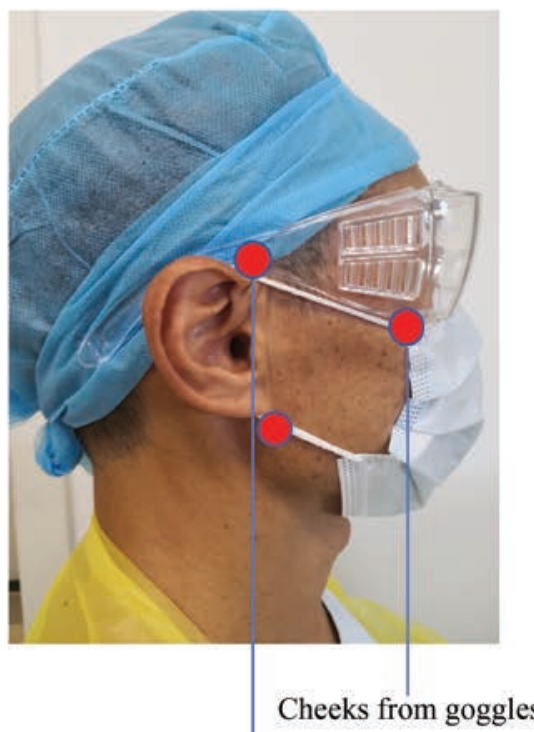

Above the ears from mask strap

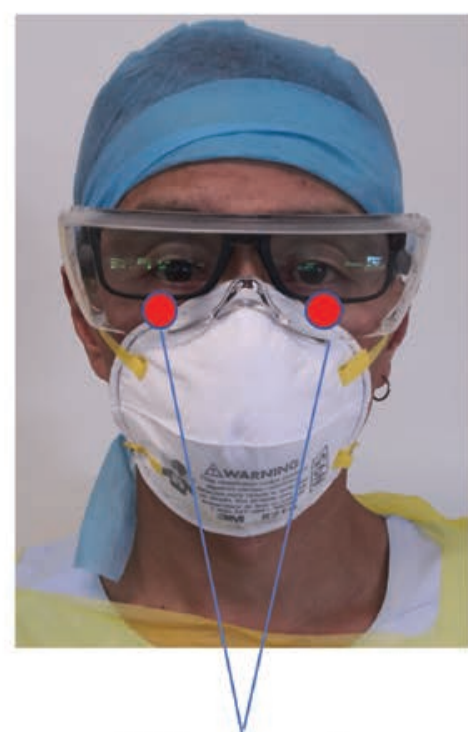

Under eyes from glasses and goggles 
advised to weigh the risks and benefits of this practice and consider their local facility policies ${ }^{20}$.

Given the impact of the COVID-19 global pandemic on healthcare staff, interventions to assist staff wellbeing are paramount ${ }^{22}$. The aim of this paper is to present a tip sheet to assist in preventing the occurrence of DRPI in staff wearing PPE for prolonged periods.

\section{Methods}

We formed a local expert group comprised of six skin integrity specialists and researchers in two Australian states, Queensland and New South Wales. We used an iterative consensus process for group decision-making where information generated from iteration was disseminated to group members via email; this supported the group members' decision-making through structured discussion ${ }^{23}$.

We classified a prolonged period in PPE as greater than 2 hours. Consultation was also carried out with infection control experts, along with a brief safety trial of the proposed strategies conducted by expert group members to ensure correct fit and seal of the masks was maintained as per local state guidelines ${ }^{6,7}$. We sought email feedback from staff on their experiences of applying and wearing the skin protection strategies.

We used communication via email; emails were distributed to all group members using the 'reply all' function. Key documents available at the time $e^{8,18-21}$ were disseminated to the group to inform group decision-making. Further, content of the tip sheet was determined by local availability of products.

All group members replied to indicate their suggestions for, and agreement with, content and proposed changes. Changes to text and comments made to the tip sheet were performed using the edit and track changes function in Microsoft Word (Microsoft Office, 2016). Each change, or iteration, achieved $100 \%$ group agreement. The tip sheet was developed by the

Figure 5. Skin protection information

- Wearing of PPE masks and eye protection when caring for COVID-19 patients or undertaking screening/ swabbing procedures for prolonged periods causes sweating and areas of pressure points on all areas of the skin in contact with PPE, for example the bridge of the nose, cheek bones and above the ears.

- Follow the intensive care unit/hospital policy for the use, and application, of PPE.

- Use of a skin barrier protectant (e.g. Cavilon ${ }^{\text {TM}}$ ) and a dressing pad (Mepilex ${ }^{\circledR}$ Lite) or silicone tape (Mepitac $^{\circledR}$ or Sofsicure ${ }^{\circledR}$ ) as an interface between PPE and the skin to alleviate pressure, shear and friction is recommended. expert group using key communication strategies to attract the readers' attention and promote ease of understanding with straightforward provision of key information ${ }^{24}$.

A near final draft was then circulated to senior nursing leadership in the intensive care service of one facility for their review and comment. Changes to the tip sheet were then made and consensus achieved within the expert group. The tip sheet was circulated to staff in the intensive care units and the COVID clinics of two healthcare facilities, one in Queensland and one in New South Wales, using multiple strategies such as email, posters displayed in prominent clinical areas, word of mouth and the expert group members providing information face-to-face. We also placed a poster of the tip sheet at the PPE donning station as a visual prompt. This was accompanied by baskets of the appropriate prophylactic dressings and materials/product supplies placed with the PPE in the clinical PPE robing to ensure easy access for staff.

Feedback was sought from staff via email or verbal face-toface communication with one of the authors at each facility.

\section{Results}

The tip sheet provides staff with information on skin protection (Figure 5), the principles involved (Figure 6), and a step-by-step guide to preparing and applying a quick and efficient method of skin protection using a dressing foam pad (Figure 7) and a silicone tape and adherent prophylactic dressing (Figure 8). The suggested prophylactic dressings and materials proposed in the tip sheet were chosen based on clinical availability and expert opinion. Further options for staff who are allergic to silicone or protective rubber gloves are provided in Figure 9.

Feedback was received from 12 staff members; this highlighted two key issues - fading/reduction of skin redness and slippage of prophylactic dressings.

Figure 6. Principles involved in skin protection

- Skin protection tips should be applied at the discretion of each RN.

- Facial prophylactic dressings are single use only.

- Facial skin protection should be applied after hand hygiene and first before donning PPE.

- Each time prophylactic dressings are applied to the face, the integrity of the seal of the mask (PPE) must be checked.

- Facial skin protection should be removed as the last step when removing PPE. 
Figure 7. Step-by-step guide to preparing and applying a quick and efficient method of skin protection using a dressing foam pad

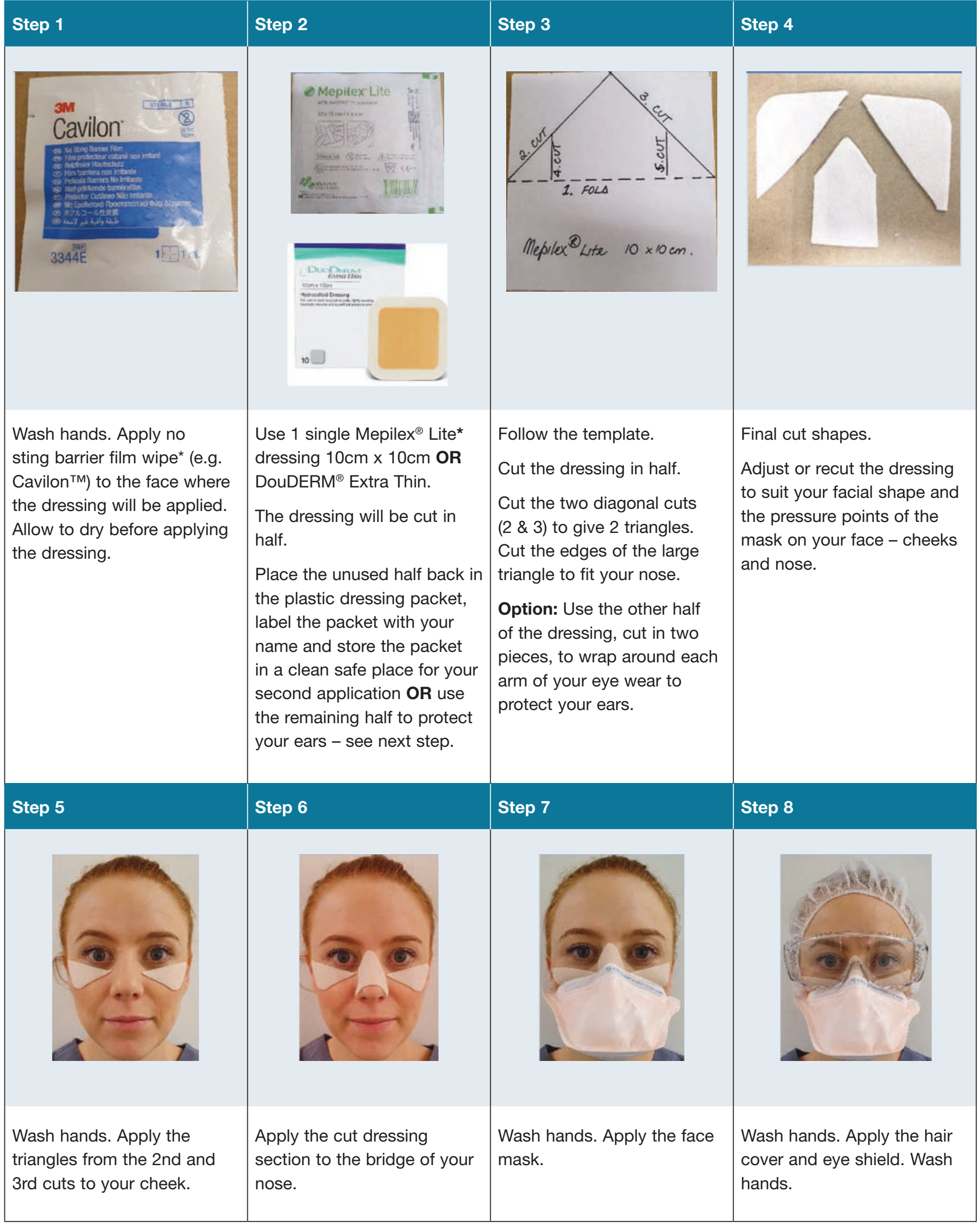

* The use of products in this tip sheet is off label 
Figure 8. Step-by-step guide to preparing and applying a quick and efficient method of skin protection using a silicone tape and an adherent prophylactic dressing

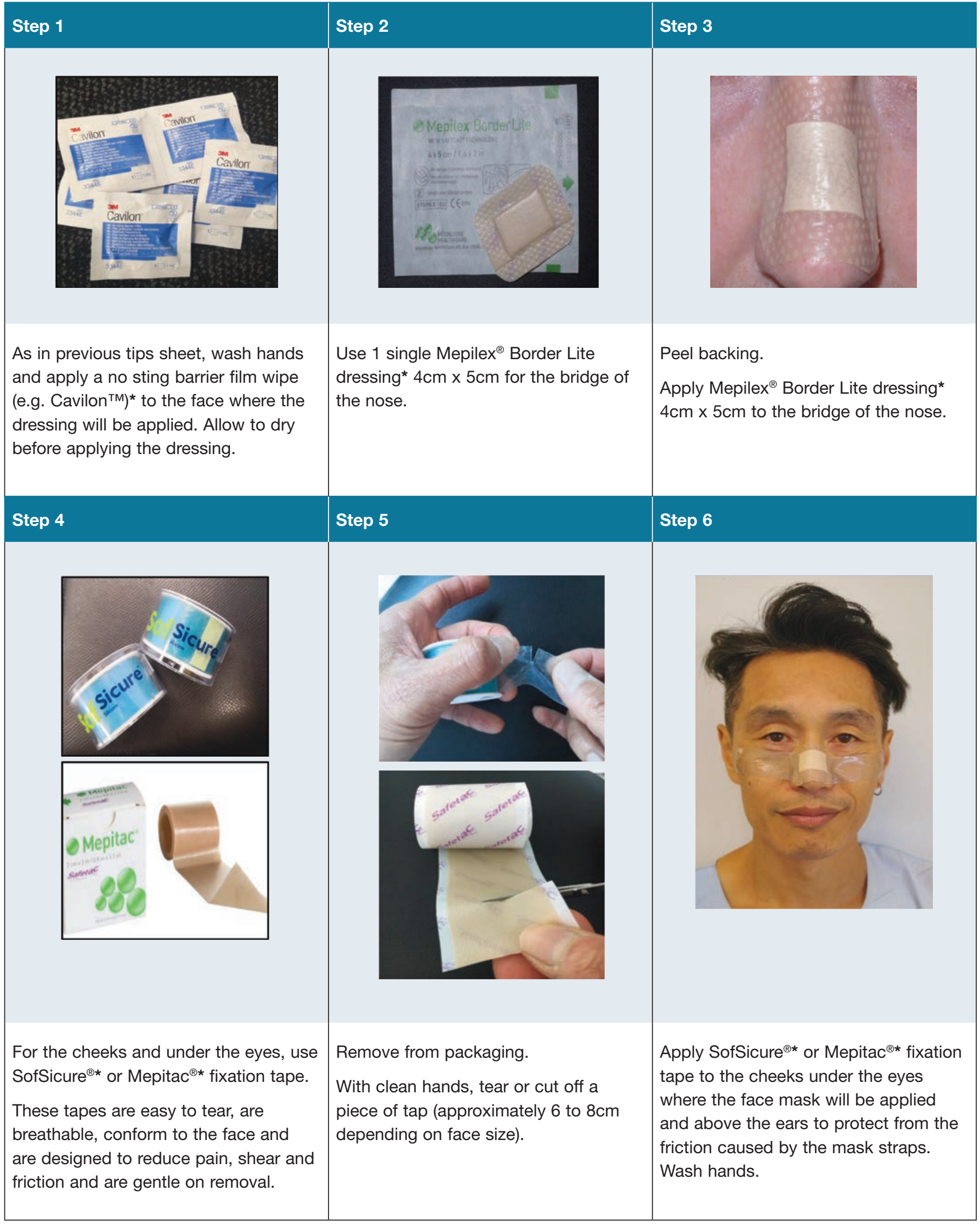


Figure 9. Further options for staff who are allergic to silicone or protective rubber gloves

- Those staff members allergic to silicone can use Comfeel ${ }^{\circledR}$ Plus Transparent (Coloplast) dressing in the same manner.

- For irritant dermatitis caused by prolonged wear of disposable protective rubber gloves, consider use of a barrier hand cream, such as Silic $15^{\mathrm{TM}}$ (Ego), to be applied as the last step before donning protective gloves.

\section{Fading/reduction of skin redness}

Feedback included the following:

I initially used a FLUIDSHIELD* N95 Filter Respirator (Halyard Health). My nose and cheekbones were heavily marked for more than 2 hours, without skin breakdown. I then put on the Mepilex Lite ${ }^{\circledR}$ (Mölnlycke ${ }^{\circledR}$ ) [dressing]. It sealed better. Marks on my cheekbones faded noticeably within an hour [RN1].

On my first break I noticed I had a lot of redness from my duckbill mask - particularly on the bridge of my nose. After noticing this, I used the supplied Mepilex Lite ${ }^{\circledR}$ [dressing] as protection; however, it weakened the seal of the mask and made the mask slip down slightly [RN5].

I changed to a 3M ${ }^{\mathrm{TM}} \mathrm{N} 95$ [mask] due to constant leaks and fogging of my glasses with the FLUIDSHEILD*. The bridge of my nose was not red or marked when I wore the $3 M^{\mathrm{TM}}$ one as it already has foam on the nose bridge. However, my cheekbones were heavily marked. This largely resolved with the Mepilex Lite $^{\circledR}$ [RN3].

When I first wore my mask and googles, I experienced a lot of pain on the bridge of my nose and above my ears. My nose and cheeks were red. I used the SofSicure ${ }^{\circledR}$ [Sentry Medical] [silicone fixation] tape behind my ears and across my cheeks, as well as the Mepilex ${ }^{\circledR}$ Border Lite $4 \times 5$ [cm] on the bridge of my nose, it provided a lot of relief and I did not get red marks [RN2].

\section{Slippage of prophylactic dressings}

Feedback included the following:

I found that applying a Cavilon ${ }^{\mathrm{TM}}$ wipe [3 $\left.\mathrm{M}^{\mathrm{TM}}\right]$ before putting on the Mepilex Lite ${ }^{\circledR}$, reduced the movement. I found it to be a must [RN1].

I tried DuoDERM ${ }^{\circledR}$ Extra Thin [ConvaTEC], as suggested by other nursing staff. This was very easy to apply and stuck very well for long hours. However, it was very painful to remove [RN4].

The SofSicure ${ }^{\circledR}$ on my cheeks and Mepilex Border Lite ${ }^{\circledR}$ on the bridge of my nose, did not get sweaty like the sticky hydrocolloid dressings I used the other day. Both the
Mepilex Border Lite ${ }^{\circledR}$ and SofSicure ${ }^{\circledR}$ were very easy to remove and did not cause any pain [RN2].

\section{Discussion}

This tip sheet presents a concise and staged approach to developing skin protection for staff wearing PPE. All PPE should be donned and removed as per local policies. This tip sheet focused on relief of pressure from face masks and eye wear. It is intended as a rapid quick guide to be laminated and placed in the clinical area where staff are donning PPE.

We used four types of thin prophylactic dressings, Mepilex ${ }^{\circledR}$ Lite, a self-adherent, easy to cut, soft silicone foam dressing to minimise trauma to the facial skin, DuoDERM ${ }^{\circledR}$ Extra Thin, a hydrocolloid dressing to prevent skin breakdown from friction, and Mepilex ${ }^{\circledR}$ Border Lite for the bridge of the nose. We chose thin prophylactic dressings to ensure comfort while maintaining the integrity of the seal of the mask ${ }^{25-27}$. We consulted with infection control services that endorsed the use of the prophylactic dressings providing the mask has a good seal. We also used silicone fixation tape (Mepitac ${ }^{\circledR}$ $\left[\right.$ Mölnlycke ${ }^{\circledR}$ ] and SofSicure ${ }^{\circledR}$ ) that is easy to tear, breathable, conforms to the face and designed to reduce shear and friction. Mepitac ${ }^{\circledR}$ and SofSicure ${ }^{\circledR}$ are gentle on removal to reduce pain ${ }^{28}$. To improve prophylactic dressing adherence in potentially humid conditions with prolonged PPE wear, we recommend the application of a barrier, for example Cavilon ${ }^{\mathrm{TM}}$ No Sting Barrier Film wipe, an alcohol-free terpolymer barrier that provides a protective coating on the facial areas where the dressings will be applied ${ }^{27,29}$. When applying the barrier film, wiping the eye area should be avoided.

We opted for simple cut-out steps for the prophylactic dressings. Further, for the template prophylactic dressing cutting option we suggested the use of one single prophylactic dressing per time; a saving of resources. Staff may individualise the template and cut the prophylactic dressing to suit their own facial contours. We acknowledge that the use of the prophylactic dressings and tape as suggested in this tip sheet is off label. The strategies suggested in this tip sheet are intended to minimise the forces of friction and pressure as well as moisture and humidity caused by the prolonged wear of PPE, especially masks. As such, they are the basis of a degree of trial and error and the tip sheet is a fluid, living document. Further, each clinician should weigh the risks and benefits and individualise the suggested strategies to suit their own unique facial contours. However, the underlying principle of adherence to local infectious disease guidelines ${ }^{6,7}$ remains - that the integrity of the seal of the mask must be checked before entering the isolation room or bedspace and that the seal must be maintained throughout.

The skin should be protected by cleaning prior to the application of barrier films and prophylactic dressings. In line with best practice guides to prevent DRPI in patients ${ }^{9,30}$, a recent international consensus document on $\mathrm{DRPI}^{8}$, and a professional organisation's position statements ${ }^{20}$, 
we recommend for healthcare staff that the prophylactic dressing interface between the skin and PPE, and the facial skin, should be assessed at least 4-hourly. Finally, following removal of PPE according to local facility guidelines and the prophylactic dressings, the skin should be cleansed and a moisturiser applied ${ }^{18-21}$.

\section{Future work in this field}

Previous literature addressing this issue is scant $^{16}$ and reference is only made to skin lesions such as rash, itching or erythema in staff wearing PPE. With the COVID-19 pandemic, we now see evidence, largely through numerous social media channels, of skin injuries caused by PPE present on the faces of healthcare staff (Figures 2 and 3). We suggest that such skin injuries are DRPI and should be assessed, staged and recorded or documented as such. Further research is needed in this field to identify the prevalence and incidence of DRPI in healthcare staff caused by PPE in order to evaluate the maintenance of integrity of mask function when a prophylactic dressing is applied.

\section{Limitations}

There are some acknowledged limitations to this work, namely the need to extrapolate evidence and guidance from other contexts (DRPI experienced by patients) (indirect evidence) when direct clinical evidence on this issue is unavailable. In the interest of meeting an urgent clinical need, we used an iterative group consensus process to facilitate rapid development of a tip sheet. Use of a structured Delphi process for future work in this area would provide reliable quantifiable group response and participant anonymity.

\section{Conclusion}

The occurrences of DRPI in frontline healthcare staff wearing PPE is an emerging and significant issue. These tip sheets provide a quick overview and potential solution options for healthcare staff to protect their skin. Further empirical work is required to address this issue and disseminate effective, practical, evidence-based solutions.

\section{Conflict of interest}

The authors declare no conflicts of interest.

\section{Funding}

The authors received no funding for this study.

\section{References}

1. World Health Organization. Coronavirus disease 2019 (COVID-19) situation report 51; 2020 [cited 2020 Jun 4]. Available from: https://www.who.int/docs/default-source/ coronaviruse/situation-reports/20200311-sitrep-51-covid-19. pdf?sfvrsn=1ba62e57_10

2. World Health Organization. Coronavirus disease 2019 (COVID-19) situation report 135; 2020 [cited 2020 Jun 4]. Available from: https://www.who.int/docs/default-source/ coronaviruse/situation-reports/20200603-covid-19-sitrep-135. pdf?sfvrsn=39972feb_2
3. World Health Organization. Infection prevention and control during health care when novel coronavirus (nCoV) infection is suspected: interim guidance; 2020. Available from https://www. who.int/publications-detail/infection-prevention-and-controlduring-health-care-when-novel-coronavirus-(ncov)-infection-issuspected-20200125

4. ANZICS. The Australian and New Zealand Intensive Care Society (ANZICS) - COVID-19 guidelines, version 1; 2020. Available from https://mcusercontent.com/03cbd5b8a6d36c351c46c235e/ files/86e36972-a552-45da-8eab-8fd8c52a788d/ANZICS_ COVID_19_Guidelines_Version_1.pdf

5. Australian Government, Department of Health. Australia health sector emergency response plan for novel coronavirus (COVID19). Australian Government; 2020. Available from https://www. health.gov.au/resources/publications/australian-health-sectoremergency-response-plan-for-novel-coronavirus-covid-19

6. New South Wales Government. Clinical Excellent Commission. Personal protective equipment; 2020 [cited 2020 Apr 14]. Available from: http://cec.health.nsw.gov.au/keep-patients-safe/ COVID-19/standard-and-transmission-based-precautionsincluding-ppe.

7. Queensland Government. Interim infection prevention and control guidelines for the management of COVID-19 in healthcare settings. Version 1.10; 27 March 2020.

8. Gefen A, Alves P, Ciprandi G, Coyer F, Milne C, Ousey K, Ohura N, Waters N, Worsley P. Device-related pressure ulcers: SECURE prevention. J Wound Care 2020;29(Sup2a):S1-S52. doi:10.12968/jowc.2020.29.Sup2a.S1

9. European Pressure Ulcer Advisory Panel (EPUAP), National Pressure Injury Advisory Panel (NPIAP), Pan Pacific Pressure Injury Alliance (PPPIA). Prevention and treatment of pressure ulcers/injuries: clinical practice guidelines. The international guideline. 3rd ed. Emily Haesler, editor. EPUAP, NPIAP, PPPIA; 2019.

10. Coyer FM, Stotts NA, Blackman VS. A prospective window into medical device-related pressure ulcers in intensive care. Int Wound J 2014;11(6):656-64.

11. Black J, Alves P, Brindle CT, Dealey C, Santamaria N, Call $\mathrm{E}$, Clark M. Use of wound dressings to enhance prevention of pressure ulcers caused by medical devices. Int Wound $\mathrm{J}$ 2015;12(3):322-7.

12. Edsberg LE, Black JM, Goldberg M, McNichol L, Moore L, Sieggreen M. Revised national pressure ulcer advisory panel pressure injury staging system. J Wound Ostomy Continence Nurs 2016;43(6):585-97.

13. Hanonu S, Karadag A. A prospective, descriptive study to determine the rate and characteristics of and risk factors for the development of medical device-related pressure ulcers in intensive care units. Ostomy Wound Manag 2016;62(2):12-22.

14. Barakat-Johnson M, Barnett C, Wand T, White K. Medical device-related pressure injuries: an exploratory descriptive study in an acute tertiary hospital in Australia. J Tissue Viability 2017;26(4):246-53.

15. Barakat-Johnson M, Lai M, Wand T, White K, Coyer F. The incidence and prevalence of medical device-related pressure injuries in intensive care: A systematic review. J Wound Care 2019;28(8):1-8.

16. Foo CCl, Good ATJ, Leow Y-H, Goh C-L. Adverse skin reactions to personal protective equipment against severe acute respiratory syndrome - a descriptive study in Singapore. Contact Dermatitis 2006;55:291-294. 
17. Alqahtani JS, AlAhmari MD. Evidence based synthesis for prevention of noninvasive ventilation related facial pressure ulcers. Saudi Med J 2018;39(5):443-452. doi:10.15537/ smj.2018.5.22058.

18. Alves P, Moura A, Vaz A, Ferreira A, Malcato E, Mota F, Afonso G, Ramos P, Dias V, Homem-Silva P. PRPPE guideline COVID-19: prevention of skin lesions caused by personal protection equipment (face masks, respirators, visors and protection glasses. Portuguese Wound Management Association (APTFeridas). J Tissue Heal Regen 2020; Education Supp, 15 March.

19. Le Blanc K, Heerschap C, Butt B, Bresnai-Harris J, Wiesenfeld L. Prevention and management of skin damage related to personal protective equipment: update 2020. Nurse Specialized in Wound, Ostomy and Continence Canada (NSWOCC); 2020. Available from: www.nswoc.ca/ppe

20. National Pressure Injury Advisory Panel (NPIAP). Position statement on preventing injury with N95 masks; 2020. Available from: https://cdn.ymaws.com/npiap.com/resource/resmgr/ position_statements/Mask_Position_Paper_FINAL_fo.pdf

21. National Pressure Injury Advisory Panel (NPIAP). Protecting facial skin under PPE N95 face masks; 2020. Available from: https://cdn.ymaws.com/npiap.com/resource/resmgr/position statements/NPIAP_-_Mask_Injury_Infograp.pdf

22. Gefen A. Skin tears, medical face masks and Coronavirus. Wound Manage Prevent 2020 Apr;66(4):6-7.

23. Lee Y, Park YB. A proposal of iterative consensus process for group decision making. 2019 International Conference on Platform Technology and Service (PlatCon), Jeju, Korea (South), 2019, pp.1-4, doi:10.1109/PlatCon.2019.8668957.

24. Arnold EC, Boggs KU. Interpersonal relationships e-book: professional communication skills for nurses. Elsevier Health Sciences; 2019.

25. Schallom M, Cracchiolo L, Falker A, Foster j, Hager J, Moorehouse T, Watts P, Weems L, Kollef M. Pressure ulcer incidence in patients wearing nasal-oral versus full-face noninvasive ventilation masks. Am J Crit Care 2015;24(4):349-356.

26. Cohen LP, Ovadia-Blechman Z, Hoffer O, Gefen A. Dressings cut to shape alleviate facial tissue loads while using an oxygen mask. Int Wound J 2019;16:813-826.

27. Field MH, Rashbrook JP, Rodriques JN. Hydrocolloid dressing strip over bridge of nose to relieve pain and pressure form filtered face piece (FFP) masks during the coronavirus (COVID-19) pandemic. Ann R Coll Surg Engl 2020;102:391-396.

28. Taroc AM. Staying out of sticky situations: how to choose the right tape for your patient. Wound Care Advis 2015;4(6):21-26. Available from: https://www.myamericannurse.com/stayingsticky-situations/

29. Anderson D. Wound dressings unravelled. In Practice 2003; 25(2):70-83.

30. National Pressure Injury Advisory Panel. Best practices for prevention of medical device-related pressure ulcers in critical care; 2020 February. 